\title{
Archaeological tourism; characteristics and functions
}

\begin{abstract}
The aim of the present paper is to respond the basic question of "what is Archaeological tourism and what are its characteristics and functions?" the research method is descriptive and library method has been used to collect data. We have attempted to explain archaeology and study its characteristics and functions, concerning generalization of archaeology. The findings of the study revealed that the Archaeological tourism (AT), with regard to its characteristics and various functions, has promoted democratic archaeology; and that Archaeological tourism is an efficient instrument to interact heritage and tourism in archaeological sites; and to change archaeological attractions into the tourism products and ultimately making archaeology knowledge public and generalize it.
\end{abstract}

Keywords: archaeological tourism, development, people, archaeology
Volume 6 Issue 2 - 202I

\author{
Behrouz Afkhami \\ Department of Archaeology, University of Mohaghegh Ardabili, \\ Iran
}

Correspondence: Behrouz Afkhami, Department of

Archaeology, University of Mohaghegh Ardabili, Ardabil, Iran, Tax +9804531505006, Fax+9804531505006,

Email bafkhami@uma.ac.ir

Received: February 23, 202 I | Published: November 17, 2021

\section{Introduction}

Accepting the fact that public support is the best stride toward legitimating an activity or knowledge, we will clearly find out the importance of generalizing the archaeology, in general and visiting the Archaeological sites, in particular. The public natures of tourism along with people's innate interest in archaeology have made it possible. Of course, such general tendencies and approaches led to innovation of an effective and efficient principle in the World Tourism Organization (WTO) which considered the basic principle of the cultural tourism as application of the human cultural heritage and participation in its promotion and improvement Cabrini. ${ }^{1}$ The same general comprehensive principle makes the relation between scientific and applied archaeology as an inevitable course to study cultural heritage and tourism. The modern approaches in the world scientific communities and holding periodical and regular conferences have made clear the importance of the problem. Since, the archaeological methods of archaeology and the ways for people to achieve the predetermined results have been considerable; archaeology has taken steps toward generalizing itself. However, it seems that the best step is relating archaeology to tourism. This paper attempts to explain characteristics and functions of the archaeological tourism in the road toward generalizing the archaeology knowledge.

\section{Purpose}

The purpose of this article is to emphasize the sustainable interaction between archeology and tourism. Areas of joint collaboration have led to the creation of a joint study field, "Archaeological Tourism". Archaeological tourism as a specialized field has features and functions that show the importance of the issue in the field of preservation and promotion of cultural heritage. Promotes tourism and minimizes the negative consequences of tourism development in heritage environments. Introduces people to cultural heritage; So that people have a protective view in the face of cultural heritage, rather than a destroyer.

\section{Method}

The research method is based on the purpose of the article of an applied type that aims to interaction archeology with tourism. Some of the thoughts of archaeologists who think only of the mere physical preservation of artifacts are in conflict with the motives of tourism and the purpose of the tourism being visited. The theoretical concepts of this research have been compiled in the form of a library and referring to the relevant theoretical foundations and the real problems, features and functions of this field have been compiled.

\section{Background}

The interaction between archeology and tourism has an ancient history that probably implicitly a date back to the Renaissance, but little scientific document is available on the title of the article. The book "Introduction to the Relationship between Archeology and Tourism" is one of the important sources written in connection with the article. And other sources refer to them in the references.

\section{Approaches of the world archaeological tourisms organizations}

Cultural tourism and its sustainable development have been considered as the WTO's agenda since the early 1970s. WTO pays special attention to the result of consociation of heritage and tourism to achieve sustainable cultural tourism. The problem has been emphasized in the "global ethical code" for tourism by WTO members in October 1999 and approved by the UN General Assembly in December 2001 Cabrini. ${ }^{1}$ Also UNESCO's mid-term strategy (the 11th strategic goal 2008-2013) emphasizes on preservation and sustainable enhancement of the cultural tourism and its effects on social consolidation and peace UNESCO ${ }^{2}$ According to the estimates of WTO in 2006 over half of the international tourists have visited the main cultural tourism sites Timothy. ${ }^{3}$ The importance of cultural heritage and being a basis for cultural economy have encouraged the authors concentrate on cultural tourism Choi et AL. ${ }^{4}$ The scientific and fundamental approach of the organizations in charge of heritage and tourism make the importance and universality of the problem more obvious. Archaeology and tourism are inseparable components of the heritage and cultural tourism Giraudo. ${ }^{5}$ Archaeology and tourism are profoundly interconnected; this connection has started from the very beginning of the 16th century and early grand tours and continued; so that the authorities of the great digging projects call people for participation in their operations. Dig for a day finding is one of the cases led to interesting tourism and exploration experiences. A tourist may visit an under-exploration site and take photos Baram. ${ }^{6}$

Tourism success becomes more clear with archaeology, i.e. tourism sites are generally famous archaeology sites such as the world heritage sites (Persepolis, Egyptian pyramids and Pantheon, etc.). On the other hand, tourism sources facilitate preservation and presentation of the sites. This finding provided us with a new 
understanding of historical and archaeological sources, and puts the archaeological activities in the framework of Archaeological values and sustainment principles, based on a comprehensive approach. In this regard, archaeological findings and documents are value sources for scientists and researchers as well as an economic source for the society and government. Success of an archaeological site with such an approach increases its value and importance from the view point of people who live around the site and leads to public protection of the archaeological heritage sites. Concerning the comprehensive approach and the sustainable development principle in archaeological activities, archaeological tourism is not contrary to professional nature of the archaeology; because archaeology is not due to revive the identity and it is not an instrument for preparing and expressing the earlier objects, imaging and gentility, but it is naturally in charge of other values including development process in the society. Archaeological tourism presents a democratic image from archaeology and may be highly effective in development of archaeology knowledge. Furthermore, it is efficient in protection of sustainable development of cultural heritage and generalizing it Afkhami. ${ }^{7}$ Archaeological tourism is among the application of the applied archaeology and a part of developing archaeology approach in which public participation and support are of great importance. The established relations, confidence and mutual respect are the key factors in development of archaeology. Making people and archaeology closer to each other is an incentive and basis for development of cultural policy, aiming at respecting for archaeology and its methods. Survival of archaeologists depends on their concerns about the applied tasks Downum et al. ${ }^{8}$; Brighton. ${ }^{9}$ Attention to the development of education in societies based on archaeology has helped the addresses preserve and protect various cultural values Jameson. ${ }^{10}$

That is why, the heritage tourism is called curatorial approach; because it promotes heritage Garrod et al. ${ }^{11}$ Archaeological tourism studies the ancient societies' margins, archaeological sites and the related courses including history and archaeology, people and life styles, cultural diversity, art and architecture, food and drinks, local products, social, economic and political structures and perspectives Afkhami. ${ }^{7}$ Archaeological tourism is an alternative for cultural tourism in the framework of tourism activities. The purpose is to increase eagerness and interest in history, archaeology and historical sites. Archaeological tourism is in fact visiting the ancient perspectives and sites Baram. ${ }^{6}$ It is also a component of heritage tourism or cultural heritage tourism and in fact is inside it. Actually, heritage tourism is a tourism which concentrates on the procedures and quality of the sites visiting. Archaeological tourism attractions are of great importance for the tourists who search for archaeological ornaments, site gentility and nostalgic senses. Tourists change into some part of the local and regional socio-economic areas when they enter the ancient sites. Therefore, archaeology is considered as a component of developing processes Giraudo. ${ }^{12}$ The main purpose of the archaeological tourism is creating and increasing the interest in archaeology and history, historical and ancient monuments, development of cultural heritage and satisfying the curiosity and perfection senses among those people who are interested in thinking and understanding the ambiguities of the ancient civilizations. In this kind of tourism, the tourists are interested in mutual interaction with the materials remained from the past and in their nature. The sense is achieved just through visiting the ancient valuable sites. Archaeological tourism has numerous capacities Robb. ${ }^{13}$ applied in some developing countries. However, application of this finding is more crucial in developing countries; because they face lack of sufficient budget for preserving and protecting the heritage Timothy et al. ${ }^{14}$ Also, it is necessary to satisfy heritage purposes for preserving sustainable tourism and heritage; and encourages cooperation and participation principle as one of the crucial advantages of the sustainable development Timothy et al. ${ }^{14}$ Figure 1 shows the characteristics and functions, knowledge and the related courses to archaeological tourism.

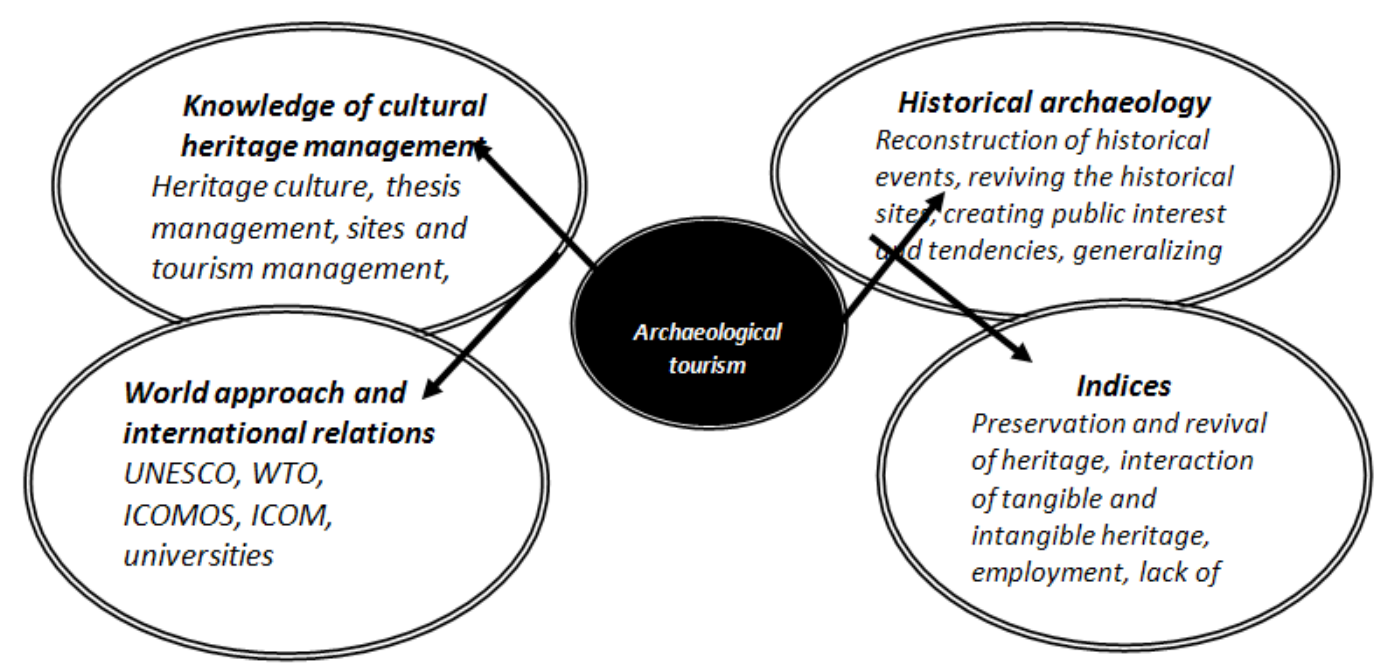

Figure I Knowledge and courses related to archaeological tourism; characteristics and function.

\section{Characteristic and function of archaeological tourism Characteristics}

The archaeology sources are considered as tourism sources, Lack of alternative because:

- They have appeared in long term;

- They are attractions with visiting possibilities;

- They are tangible. ${ }^{7}$
International laws and charters have emphasized on human heritage widely since the early $1950 \mathrm{~s}$ Vecco. ${ }^{15}$ Archaeological tourism sources are not revivable and consequently have no alternative. If they are hurt or transformed, they may not be reconstructed; because they have formed in long term and during complex processes. Hence, 
it is necessary to preserve and protect the archaeological tourism, precisely.

\section{Being unique}

The archaeological tourism sources are valuable and unique. They have been created by special men and in a special environment in ancient times and got more value through time passage. Any hurt would be permanent, in this regard. Therefore, tourism sources are to be used just through presenting them in a different way. Concerning such characteristics, it is a must to emphasize on protection and sustainable development, when we attempt to transform archaeological sources into tourism products.

\section{Expansion of capacities and developing new sources}

Developing the new sources with special capacities and delicacy, thinking about solutions for presenting and introducing archaeological tourism attractions and sites, extension of quarters and promoting tourism sources are among solutions and methods of optimum application of the sources Timothy et al. ${ }^{14}$ Moreover, the correct and appropriate application and preservation of the valuable tourism sites is necessary. Creation of the new and unique sources must be viewed as a basic principle to attract visitors. One of the assessment criteria for tourism sources is the attraction domain; i.e. from which range and distance can tourists be attracted? These capabilities exist in archaeological tourism. The above mentioned points are apparently simple, but very tough in practice. Lack of scientific and experimental investment in archaeological tourism speeds up the archaeological heritage destruction remarkably and plays a key role in attraction of tourists as the target of a country or a region, for certain.

\section{Functions}

\section{Enhance the public knowledge and generalize archaeology}

The archaeological heritage attractions are directly related to the heritage sites' educational value. Economic techniques and models for evaluation of the heritage sites help us understand their economic values in society Choi ${ }^{4}$ Most studies reveal that people visit the heritage sites for the purpose of learning and education enhancement Timothy. ${ }^{3}$ As you know, social damages are the most potential threat for the tangible cultural heritage in every country. That is why, one may consider archaeological tourism promotion and development as a logical and thoughtful strategy for sustainable development of the archaeological heritage, enhancement of the public knowledge and increase of the archaeological sites' material and moral values. Undoubtedly, generalization of the archaeology is one of the best archaeological tourism functions. As it was mentioned earlier, archaeological tourism is one of the most crucial ways of heritage preservation and development, specifically in developing countries. Experiences show that cultural heritage sites moved toward recession with no tourism interaction, and vanishing. They may not bear isolation, plunder, weather effects and other destructive factors. Lack of income permits no money making and preservation even at lowest level. On the other hand, the host community would not assume any symbolic and cultural value when the sites have been deserted; meanwhile if they are publicized and prepared for public visits, they will be kept in good conditions and with high dignity which follows by minimal compulsory preservation and protection Cabrini. ${ }^{1}$ Sustainable preservation of these material and moral sources improves public inferences, specifically among the local population. More importantly, heritage tourism introduces cultural and historical backgrounds of a region and enhances the national identity Yang et al. ${ }^{16}$ Archaeological tourism has revived archaeology sites and ancient customs and models. It also connects the ancient characteristics with those of future through reduction of poverty, and ultimately promotes the life quality of the local population through providing more socioeconomic opportunities. In this way archaeological tourism is an efficient finding to make archaeology knowledge popular.

\section{Reconstruction of the historical events}

Although archaeological sources may attract tourists by it, creating unique attractions with regard to existing sources may motivate tourists to select ultimate target as a fundamental principle. Reconstruction of the ancient life and specifically the vital historical events based on the archaeological data increases tourism attractions a site and creates unique attractions. Most of historic monuments and places do not remain in the visitors' minds and memories but the historical events are never forgotten. Despite of close relations between the archaeological tourism and historical sites as well as the cultural works related to the modern social and political systems for the subjective and tangible reasons, reconstruction of the prehistoric lifestyle using cultural-material instruments plays an extraordinary role in making people familiar with the prehistoric life style and procedures in an objective manner

\section{Revival of material and moral heritage}

Material and moral (tangible and intangible) heritages are inseparable parts of the ancient cultures reconstruction. Tangible factors are important in reconstruction of the past cultures; however there are intangible factors or moral heritage sought by tourists including individuals' life style, culture art, technology, etc. Although the factors are hardly recognizable, archaeological data in the considered sites as well as the close observed local population's life style may increase attractions of this kind of tourism activities. Creation, reconstruction, induction and showing the material and moral aspects of the ancient life is too hard, but it is highly efficient in increase of the related activities attractions. Today a monument is not consider singularly, but with its identity and capacities to be remained in the minds Vecco. ${ }^{15}$

\section{Providing comprehensive attractions data}

Archaeological tourism can affect tourists profoundly. Demonstrating tourism attraction from various aspects, solutions such as narration-like explanations and gradual preparation of tourists to make them face the archaeological sources are very useful. Observation and combining it with explanations by an archaeology educated tour guide can add the accessible sources' attractions. In an archaeological site we must explain environmental and human factors as well as their mutual effects comprehensively, in order to provide the tourists and visitors with better understanding of the site and the peripheral environment. If the information is presented comprehensively, they will have wonderful effects. Contextual inference is very vital in this regard. It is necessary for tourists to note the differences between one place and other places. Archaeological tourism promotes and proselytes this method to face archaeological sources.

\section{Reconstruction of the past products and shopping attraction}

Shopping has special attraction for tourists where they go shopping the art works and handicrafts, without stealing any art work from the site. Although purchasing local foods and goods is attractive for tourists, the situation may be improved through arrangements such as manufacturing earthenware based on ancient methods which are reconstructed by digging experts, or using ancient motifs in the site as well as on the earthenware. Tourist will experience more excitement through shopping or observing the goods. This method 
is an inseparable component of the archaeological tourism which is very helpful and effective for propaganda purposes and informing the tourists about the site. One of the basic problems in archaeological tourism is enhancement of the site value and importance for the local communities. Local initiatives such as festivals, concerts and entertainment parks may speed up tourist attraction in the local communities Bowitz et al. ${ }^{17}$

\section{Creating nostalgic senses and attracting tourists from far distances}

Creation of a nostalgic sense is one of the archaeological tourism functions Giraudo. ${ }^{5}$ Presenting and reconstruction of the ancient life style is a dreamlike and incredible situation for modern and industrial man. It gives depth to the tourists' worldview and provides them with a window to watch the probable road passed by their ancestors. Moreover, archaeological tourism can motivate people from all over the world to visit wonderful tourism sources such as Egyptian Pyramids, Artemis tomb and Persepolis. ${ }^{18}$

\section{Conclusion}

Archaeological tourism is the result of tourism and archaeology interaction. Archaeological tourism is in the framework of heritage tourism and acts toward developing the tourism capacities. It is a new approach in democratic archaeology. Among the archaeological tourism characteristics and outputs one may point to helping historical events reconstruction, helping generalization of archaeology and lastly preservation of the archaeology heritage, concerning the fact that historical interests and natural tendencies of the people toward the unknown world including archaeological tourism's characteristics and outputs are tangible and objective. The archaeological tourism's findings in the first stage pursue preservation of the heritage, followed by its promotion and development. The unique indices of the archaeological tourism and creation of the new attractions differentiate it from other tourism types. Therefore, it may be considered ceaselessly and play a crucial role in target selection among the international tourists. Archaeological tourism is a bridge between the past and present. Its principles and methods are perfectly scientific and pursue the optimum application of the archaeological tourism sites as a huge tourism source. Evaluation of the various methods for tourist attraction, creation, reconstruction of the heritage attractions, thinking about plans for presenting and introducing attractions in a comprehensive way, continuous evaluation of capacities for transforming the attractions into the tourism productions in the archaeological sites, endless assessment of attractions' sustainment and preservation, and the way of presenting attractions are among the basic principles and methods of archaeological tourism in the framework of comprehensive approach and principles of sustainable development.

\section{Acknowledgments}

None.

\section{Conflicts of interest}

The author declares that there is no conflict of inertest.

\section{Funding}

None.

\section{References}

1. Cabrini L. Cultural heritage and tourism development, international conference on "Heritage new technologies and local development". Ghent, Belgium. 2002.

2. UNESCO. 2012.

3. Timothy DJ. The heritage tourist experience. Critical Essays, Volume tow, Published by Ashgate, UAS. 2007.

4. Choi AS, Brent WR, Franco P, et al. Economic valuation of cultural heritage sites: a choice modeling approach. Tourism Management. 2009;31:231-220

5. Giraudo RF. Tourism, archaeology and development. American anthropological association 108 annual meeting, University of California, Berkeley. 2009

6. Baram U. Tourism and archaeology. Encyclopedia of archaeology, ed. by Deborah M. Pearsall, Academic Press, New York. 2008.

7. Afkhami B. An introduction to relationship between archaeology and tourism. Published by tourism research, Tehran, Iran (in Persian). 2008.

8. Downum CE, Laurie JP. Applied archaeology. Human Organization. 1999;58(3):226-239.

9. Brighton SA. Applied archaeology and community collaboration: uncovering the past and empowering the present. Human Organization. 2011;70(4):344-354.

10. Jameson JH. Interpretive art and archaeology. Encyclopedia of archaeology, editor in chief De Borah M. Pearsall. Academic Press, New York. 2008:1529-1543.

11. Garrod B, Alan F. Managing heritage tourism. Annals of Tourism Research. 2000;27(3):682-708.

12. Giraudo RF. Intangible heritage and tourism development at the Tsodilo World heritage Site, PHD dissertation in anthropology, University of California, Berkeley. 2011.

13. Robb JG. Tourism and legends archaeology of heritage. In: Dallen J. Timothy, 2007. The heritage tourist experience, Volume Tow. 2001:353369.

14. Timothy DJ, Gyan PN. Cultural heritage and tourism. A regional perspective, Routledge, London and New York. 2009.

15. Vecco M. A definition of cultural heritage: from the tangible to the intangible. Journal of Cultural Heritage. 2010;11(3):321-324.

16. Yang Li, Geoffery W, Stephen LJS. Ethnic tourism development Chinese government perspectives. Annals of Tourism Research. 2006;35(3):751771.

17. Bowitz E, Karin I. Economic impacts of cultural heritage-research and perspectives. Journal of Cultural Heritage. 2009;10(1):1-8.

18. Alrawadieh Z. Using tourism in cultural heritage conservation: Taypet Zaman as case study, tourism, heritage and cultural change in the Middle East and North Africa region, Amman, Jordan. 2009. 